\title{
THE FUEL-TESTING PLANT OF THE UNITED STATES GEOLOGICAL SURVEY AT THE JAMESTOWN EXPOSITION.
}

Thi: fuel-testing work of the United States Geological Survey should be followed with close interest by all engineers, for it is important to all power consumers, being undertaken to point out new paths for the development of the natural resources of the coun try by locating, classifying, and testing all kinds of available fuel.

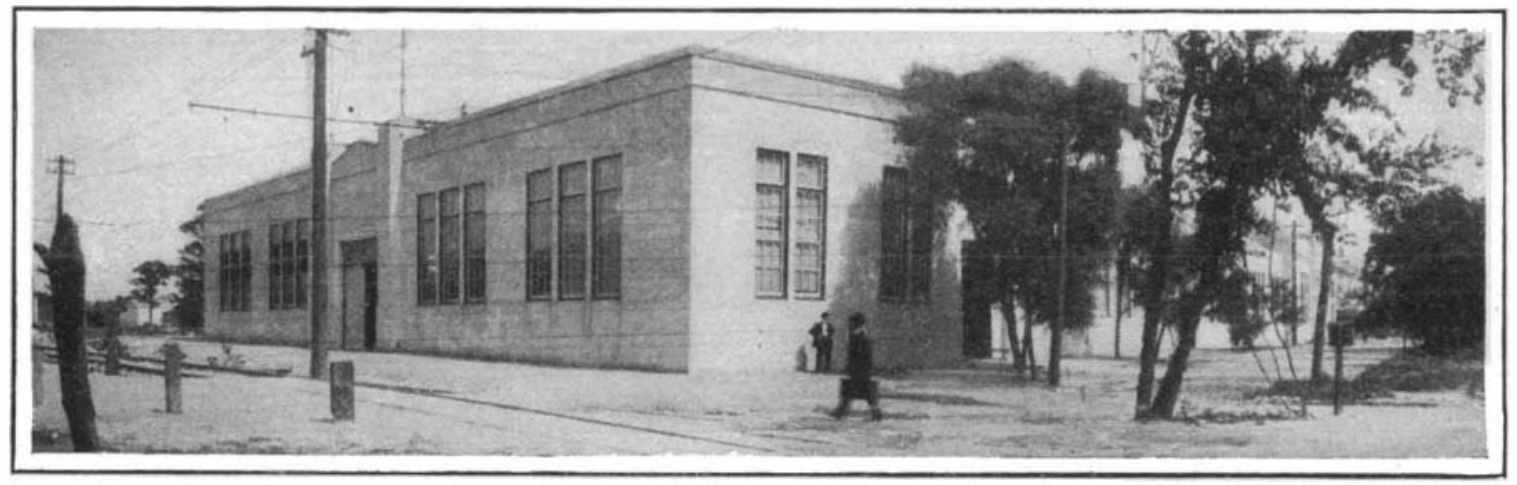

THF POWER AND ALCOHOL BUILDING AT THE JAMESTOWN EXPOSI'ION.

A report of the more recent results of this branch of the Survey's work will soon be published, and the following particulars of the plant in Virginia will meanwhile be of interest.

In the steam engineering division new apparatus has been added as follows: A 250-horse-power Babcock \& Wilcox boiler, with superheater, provided with a Roney stoker; a Jones underfeed stoker with fan added to one of the old Heine boilers; two direct-current De Laval turbine sets rate 300 horse-power at about 9,000 revolutions; also three Green Fuel Economizer Company's induced-draft fans.

The method of work planned for this section is to be slightly changed, so that instead of testing a great variety of coal, more tests will be made of the same coal, different sizes and different methods of stoking or feeding, etc., being employed with the object of determining the most economical performance under different rates of combustion and the best ratios of the entire length of the tubes twice. exhibition installed, and efficiency of the furnace alone.

\section{B Y C. T. W I L K I N SON.}

The B. \& Wr. boiler will be placed beside the two Teine boilers, which have been brought from $S t$ Louis, all three having been provided with induced draft apparatus in order to get a wide range of capa city. The Heine boiler provided with the Jones stoke has the usual arrangement for forced draft. The B. \& W. boiler was inserte partly to enable tests to \section{grate and heating surfaces. \\ (building, passes through}

be made of the same fuel with different types of boilers. It serves to represent the types employing the perpendicular now of the gases through the tubes, the parallel-now types being represented by the Heine boilers. The Heine boilers have been rebaffled or par titioned in such manner as to practically double their length by compelling all the heated gases to pass along

An additional alternating-current turbo-generator

The steam engineering division, which has now practically succeede in isolating the performance of the boiler from that of the combined performance of the boiler and furnace, will continue tests with the object of still further determining the performance

The apparatus in the producer-gas section is ar-

the meter and thence to the Westinghouse gas engine transferred from the St. Louis plant. Some slight changes have been made in this apparatus. For instance, producer No. 7 has been provided with a water seal at the base to permit the ashes to be re moved without admitting air, and several holes have been bore at different heights, to be use for extracting samples of the Exs. The purifying apparatus used at St. Louis has been removed, since experience indicates that the danger from impurities has been considerably exaggerated

A special steam pipe has been provided to insure a steady water pressure, since the pressure of the supply mains nuctuates considerably

The gas engine is belted to a 200-kilowatt Bullock generator brought from St. Louis, which serves to drive the motors for the apparatus in the building, the machine shop, the briquetting plant, the elevators, and the conveyor. Any additional load required is obtained by means of a water-box resistance, which can be regulate by the switchboar attendant, so as to maintain a steady full-load value.

The plans of this section include the following determinations

The proper length for a test run, the effect of the size of the coal, the best depth of the fuel bed the effects of rapid load variations, the maximum returns from different fuels, and the response of a producer plant to sudden demands for power

In the alcohol and gasoline engines section a new work of great importance is being undertaken. Its equipment includes two 15-horse-power, $250 \mathrm{R}$. P. M. Otto gas engines; two 15-horse-power Nash Company's engines; one 2-horse-power International Harvester Company's engine; and two John Deem engines rated at 14 and 18 horse-power respectively.

Experiments will be made covering the whole range of this field but for the present the work will be confined chieny to examinations of different carbureters, with the object of showing the lines along which a more efficient method of vaporization may be obtained Other prominent work is the examination of the kinds of fuels available, with special reference to gasoline

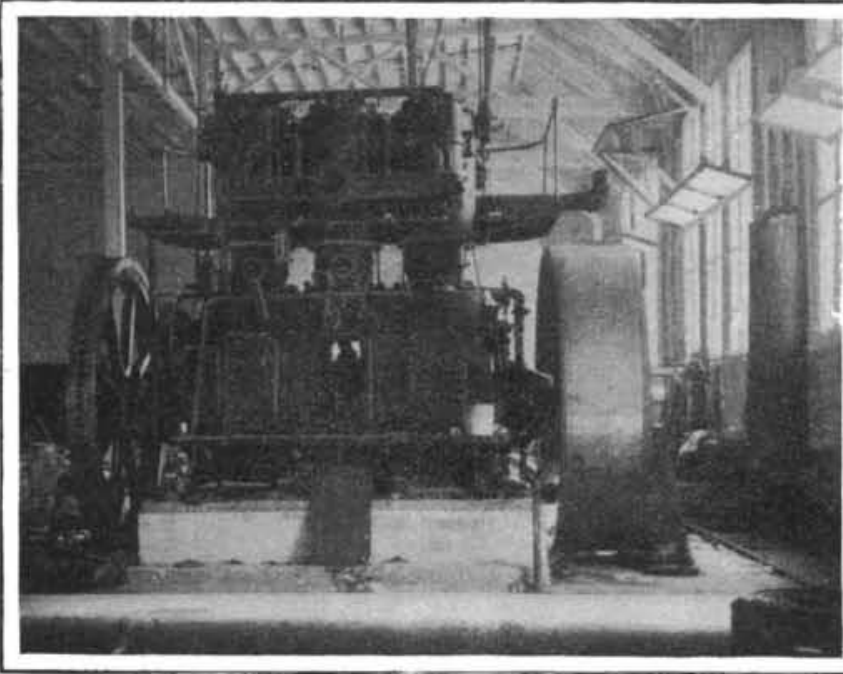

THE 235 HORSE-POWEIR WESTINGHOUSE GAS ENGINE.

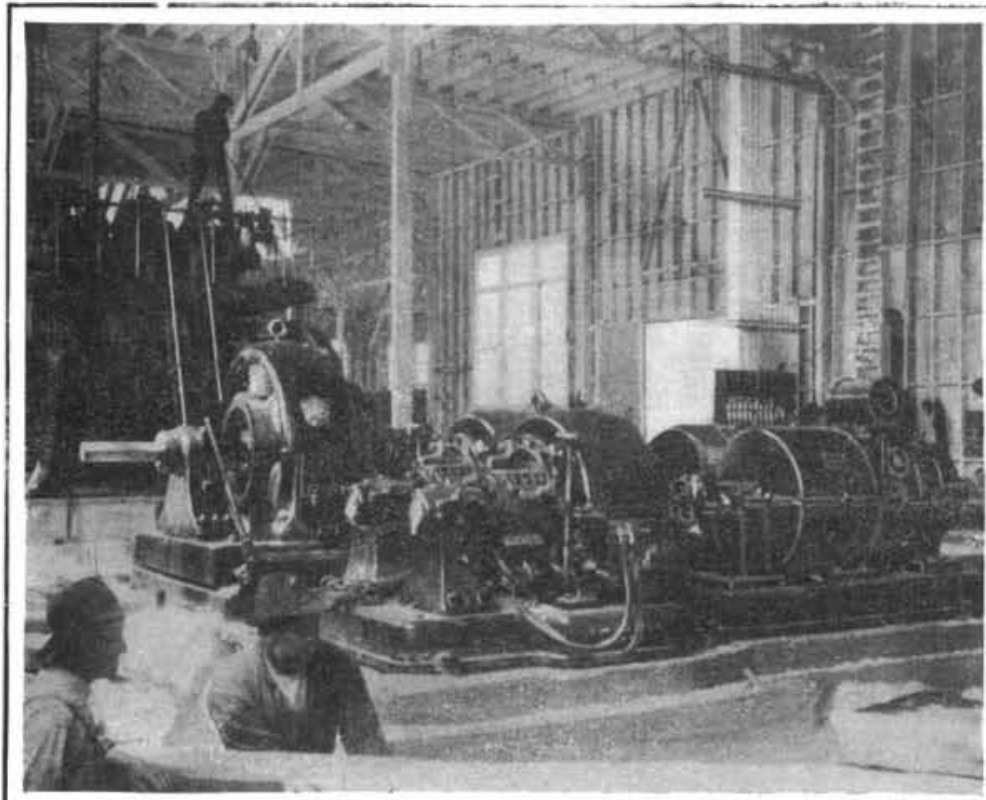

THE GAS-PRODUCER PLAN'T:
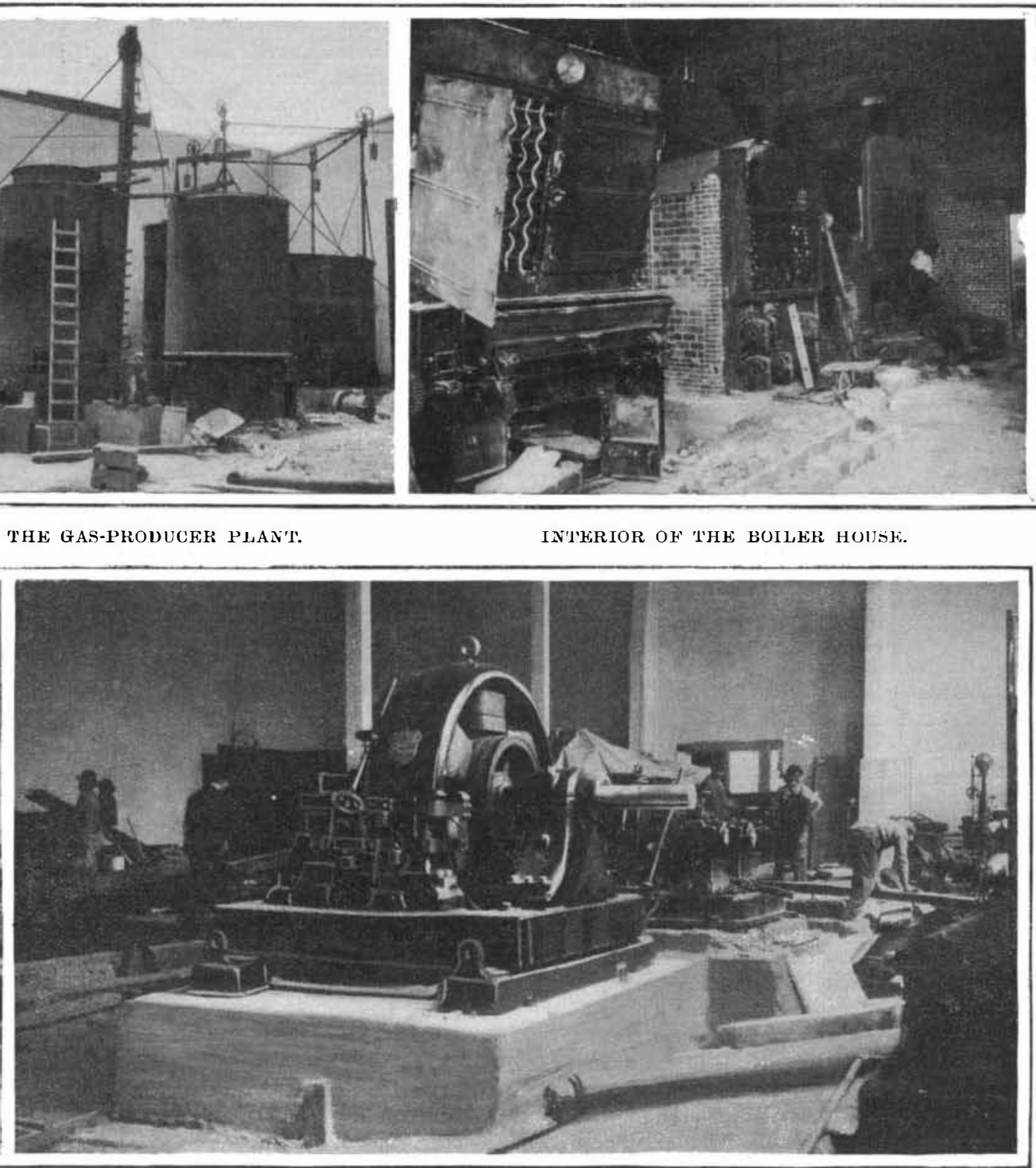

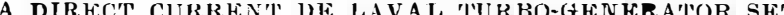

FUEL-TES'ING PLANT OF THE UNITED STATES GEOLOGICAL SURVEY AT THE JAMESTOWN EXP()SITION 
kerosene as fuel for this class of engines-an investigation necessitated by the increasing demand of gasoline and the limited supply available.

The study of the destructive distillation of coal and its combustion in gas producers, coke ovens, and furnaces, especially from the standpoint of physical chemistry, will be undertaken by several divisions.

The briquetting division, which occupies the large room at the end of the building, is putting down one large additional German briquetting machine, while the previous apparatus of English and American manufacture that was used at St. Louis is installed in the same room. The work of this division will be chiefly the manufacture of briquettes from various run-of-mine coals of the Eastern fields, which will be run-ol-mine coals of the Eastern fields, which will be engineering division. The further plans of the Geological Survey include tests dealing with the sponta neous combustion of stored coals, in which an effort will be made to simplify the methods for its prevention, while a corps of specialists will be detailed to investigate closely the whole subject of explosions in coal mines, with a view to eliminating danger from this source.

\section{NEW DEVELOPMENTS IN ARC LAMPS AND HIGH-EFFICIENCY ELECTRODES.}

\section{A COMPARISON BETWEEN METALLIC AND CARBON ARCS.}

ARCS for lighting may be formed between electrodes of many different kinds. This paper deals with the development of the so-called magnetite electrodes and of a lamp suitable for burning them. A few point of comparison between these metallic-oxide electrodes and carbon electrodes will be considered, and some of the many interesting advantages possessed by the metallic-oxide electrodes and lamp will be touched
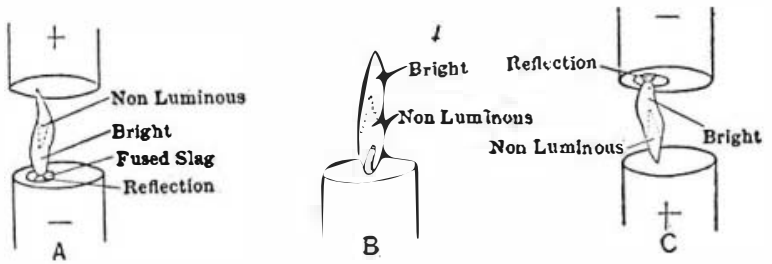

Fig. 1.-A. Metallic Arc with Negative Below. B. Candle Flame. C. Metallic Arc with Negative Above.

on. Among these are the long life, high efficiency, and good distribution and color of light.

The magnetite electrodes were so named because magnetite is usually one of the constituents of the negative or cathode, but it would be more satisfactory to as, in addition to the magnetite, there are always at least two other oxides present, namely, oxide of titanium and oxide of chromium.

These electrodes are made in a very different man ner from the carbon electrodes. As is well known, the latter are squirted or molded from a plastic mix ture and are baked, the carbon furnishing sufficient mechanical strength and electrical conductivity. metallic-oxide electrode cannot be made this way, for metallic-oxide electrode cannot be made this way, for
it is a familiar fact that a fine powder is a poor conit is a familiar fact that a fine powder is a poor con-
ductor, no matter of what it is composed, and as these ductor, no matter of what it is composed, and as these
electrodes are made for the most part from finely electrodes are made for the most part from finely
powdered oxides, it is evident that a conducting binder or a conducting case would have to be used. In practice, the mixture of oxides is tamped into a thin iron tube and the end sealed in an arc.

The oxides have distinct and separate reasons for their presence. The titanium oxide has the property of rendering the arc luminous; and it may be here noted that the metallic-oxide arc is a flame arc, the light not coming from a crater as with carbons. The oxide of iron gives conductivity to the fused mixture when cold, the other oxides being conductors only when hot. The oxide of chromium prevents a toorapid consumption, so that by its use an electrode may be given a very long life.

The positive, or anode, used with these metallicoxide negatives is generally a metal and is consumed much more slowly than the negative. This is con
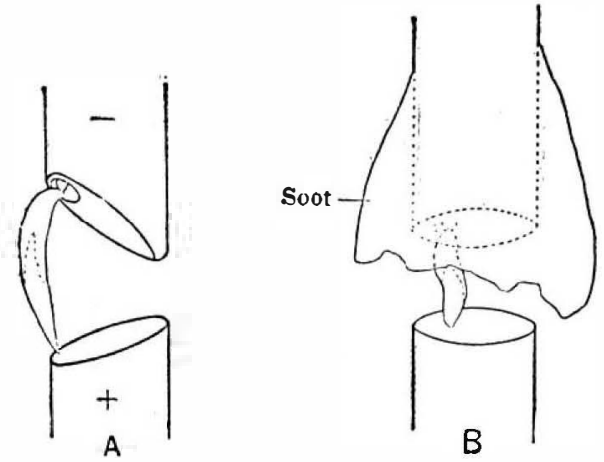

Fig. 2.-A. Showing How the Ends of Carbons Wasted Away to a Bevel Before Using the Down Draft of Air.

B Showing Accumulation of Sponge-like Masses of Soot Before Using the Down-Draft of Air.

trary to what would be expected, judging by the action of carbon electrodes.

There are a number of advantages possessed by the metallic arc over the carbon arc. In the first place, the efficiency is much better; that is, a metallic arc lamp operating on a four-ampere current with approximately 65 to 70 volts at the arc will give a light

*A paper read before the National Electric Light Association.

\section{B Y G E R G E M. L I T T LE.}

equal or superior to that of a 6.6-ampere, 75-volt, direct-current, inclosed-carbon arc lamp.

The distribution of light is far better. This is owing to the fact that in the inclosed-carbon arc practically all the light comes from the crater on the flat under-surface of the upper electrode, most of it being thrown down and not serving to illuminate the street between lamps. The light from the carbon arc itself is weak and of a blue color. This is very pronounced at times, especially if the flat under-surface of the upper electrode is somewhat inclined, thus hiding the crater. In the case of the metallic-oxide electrodes, the are is itself the source of light, practically none coming from the crater, except by reflection. The metallic arc is much like a candle flame, having its luminous and non-luminous zones. The light is brightest near that end of the arc which is next to the negative electrode, and comes from a hollow cone-shaped mantle of volatilized oxide of titanium rendered incandescent by the heat of the arc, just as in the candle flame the light comes from a hollow cone-shaped mantle of carbon particles made white hot by the heat of the flame.

The voltage required to maintain a metallic arc is less than that of an inclosed-carbon arc. It is a familiar fact that an inclosed-carbon lamp will not burn properly with the arc voltage down to 65 , while a metallic arc will burn well at less than 55. Metallíc a metallic arc will burn well at less than 55 . Metallic in different cases, while the carbon arcs are all set

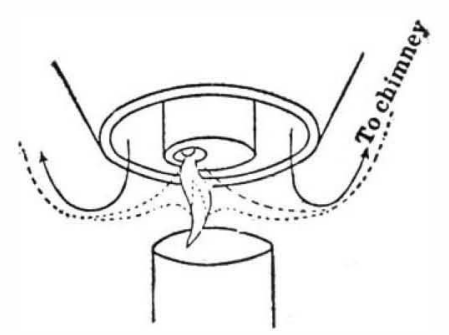

Fig. 3.-The Down-Draft of Air Forces the Soot to Take the Path Shown by the Dotted Line, Effectually Kefping It from Touching or Depositing on Anything.

at 80 . This is a very evident advantage in favor of the metallic arc, as more lamps may be put on a circuit without raising the voltage on the line

The life of carbon electrodes, as a rule, is not over 150 hours, while the metallic-oxide electrodes can go considerably longer.

The uniform white color of the metallic arc is in marked contrast to the changeabre blue and white of the inclosed-carbon arc.

As the metallic-oxide electrodes are not burned "inclosed," there is no inner globe required on the lamp.

While it looked easy to secure all of these advantages, many difficulties appeared, but they have now tages, mactically all been overcome. In the first experiments the electrodes were trimmed with the anode or positive above and the negative or metallic-oxide electrode below, just as carbon lamps are trimmed, but a number of troubles presented themselves.

First-The bright portion of the arc was near the surface of the lower electrode, which cast a large shadow.

Second-The light reflected from the brilliant surface of the fused slag on the lower electrode was thrown upward and could only be partly saved by using a reflector.

Third-An under-feed mechanism was seen to be necessary, as, contrary to the action of carbon electrodes, the negative metallic-oxide electrode is the more rapidly consumed.

Fourth-Only a comparatively short metallic-oxide electrode could be used, as a long one would necess tate the use of an unwieldy long glass globe. Thi would limit the life and could only be met by adopting a negative electrode of large diameter, which it is evident would be undesirable.

Fifth-A particularly undesirable feature was the gathering of a large amount of reddish soot that would collect in spongy masses around the electrodes, obscuring the light. This had to be removed by some mechanical means, such as scraping or shaking it off, and some receptacle other than the glass globe had to be provided to catch it.

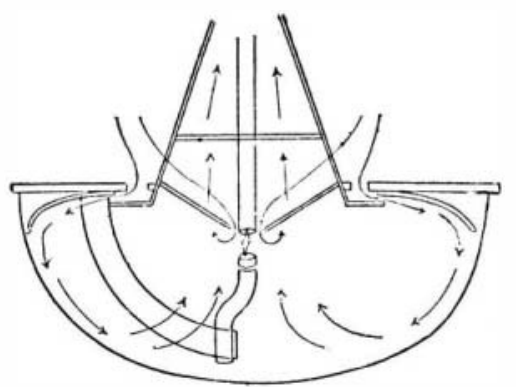

Fig. 4. - Path Taken by Air Currents in Lamp.

Sixth-The negative or metallic electrode was seen to burn to a blunt taper point, causing the arc to be very unsteady, as it tended to leave the end and run up the side in the manner of the carbon arc when flaming.

As noted above, the bright portion of the metallic arc is located near the surface of the negative electrode, and it was seen to be very desirable to burn the electrodes with the negative above, thus getting the bright portion of the arc in such a position that the shadow thrown down would be less, and that the light reflected from the brilliant surface of the fused pool of slag on the negative electrode would be thrown down and utilized instead of being thrown upward and wasted. The other advantages, noted above, possessed by the carbon lamp would be retained if this inverted position of the electrodes could be made practical.

The first attempt to burn the metallic-oxide electrode above and the metallic electrode below showed that there were serious obstacles to be overcome before it could become a practical method. In the first place the electrode would not keep a square end, but would waste away on one side, and the arc would run up this bevel, or slope, giving a very unsteady light. In the second place, the volatilized oxides of iron, chromium, titanium, and so forth would condense on the sides of the electrodes and hang down as a fringe or curtain, hiding the light.

The first means taken to overcome these troubles was the introduction of a rotating draft of air around the arc. This had the effect of forcing the arc to hold to a central position, stopped the crooked burning, and steadied the light, but did not take care of the fumes. Attempts to blow the fumes away sidewise gave only partial success. Finally, a current of air was directed down around the arc, and this gave excellent results. The electrode burned perfectly

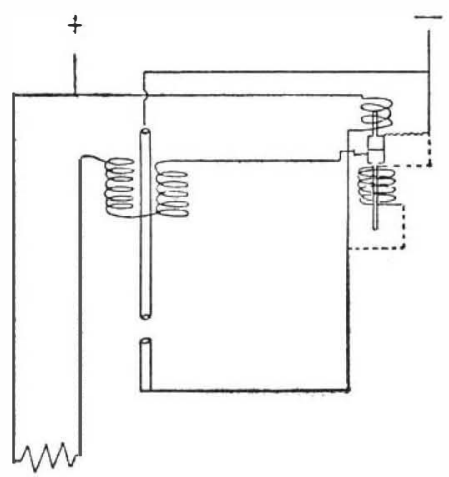

Fig. 5.-Diagram of Connections.

square, and the clean layer of air prevented any gathering of fumes. This was a very marked advance, as this did away with any need for a mechanical scraper or shaker, the soot practically all passing out of the chimney and not requiring to be caught in any receptacle, the globe remaining clean.

When burning metallic-oxide electrodes with the metallic-oxide stick below, copper was used as an anode with fair results. On reversing the position of the 